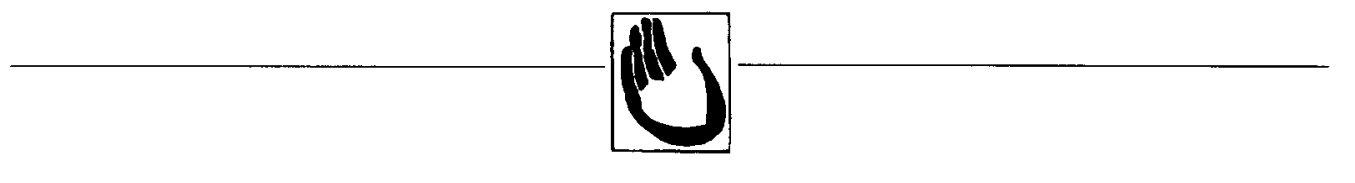

\title{
NuRSE AutONOMY AS Relational
}

\author{
Chris MacDonald
}

Key words: autonomy; ethics; professionalism; standards

\begin{abstract}
This article seeks an improved understanding of nurse autonomy by looking at nursing through the lens of what recent feminist scholars have called 'relational' autonomy. A relational understanding of autonomy means a shift away from older views focused on individuals achieving independence, towards a view that seeks meaningful selfdirection within a context of interdependency. The main claim made here is that nurse autonomy is, indeed, relational. The article begins with an explanation of the notion of relational autonomy. It then explains both the collective and the individual application of the term 'professional autonomy'. Finally, it argues that both senses of professional autonomy are best understood as relational, and suggests some implications of this conclusion.
\end{abstract}

\section{Introduction: autonomy}

This article seeks an improved understanding of nurse autonomy by looking at nursing through the lens of what recent feminist scholars have called 'relational' autonomy. The main claim made here is that nurse autonomy is, indeed, relational. Attention to the social and contextual factors that facilitate meaningfully autonomous action is crucial to advancing our understanding of the relationships between professionals and patients, as well as between different groups of professionals.

\section{Autonomy: descriptive and prescriptive}

Autonomy has both a descriptive and a prescriptive aspect, and the two are interrelated. Descriptively, autonomy is the capacity for self-governance. Prescriptively, respect for autonomy means (at least) not interfering with persons' control over their own lives and (perhaps) taking active steps to facilitate such control. Our understanding of the factual aspect of autonomy is, however, bound to influence the steps we need to take (or to avoid) in our attempts to respect people's autonomy. If our factual understanding of the preconditions for autonomous action are flawed, so will be our ethical reaction to that autonomy. For example, as Sherwin

Address for correspondence: Chris MacDonald, Department of Bioethics, Dalhousie University, 5849 University Avenue, Halifax, NS, B3H 4H7 Canada. E-mail: chris.macdonald@dal.ca 
notes, if our basic understanding of human autonomy is built on 'a model of articulate, intelligent patients who are accustomed to making decisions about the course of their lives and who possess the resources necessary to allow them a range of options to choose among', then respect for autonomy in the clinical setting will require only that we adhere to the standard for informed consent. ${ }^{1}$ That standard requires (roughly) that patients be suitably informed about their prognosis and options, and be allowed to choose among them. Such an approach ignores (albeit perhaps as a pragmatic necessity) numerous contextual factors that may prevent patients from experiencing the possibility of real choice, even though they are informed, capable, uncoerced and so on. Similarly, giving health professionals the formal authority to make a decision about patient care does not constitute professional autonomy in any meaningful sense if the institutional culture in which they are situated is not supportive of their capacity for independent judgement.

Recent feminist work on the concept of autonomy has brought attention to the networks of social relationships and interdependencies that facilitate autonomous action. Feminist scholars such as Susan Sherwin ${ }^{1}$ and Anne Donchin ${ }^{2}$ have argued that older, liberal understanding of autonomous agents as free and independent individuals is inadequate, and that we will understand autonomy better if we examine the complex webs of personal and institutional relationships that make possible, or sometimes hinder, the making of real choices. This new understanding of autonomy - known as 'relational' autonomy - claims to be a more accurate description of the actual basis for autonomous action, as well as a better grounding for our obligation to respect each other's autonomy. It is interesting that, as Sherwin herself notes, this new understanding of autonomy continues to focus on the autonomy of individuals (rather than of groups or institutions), albeit individuals who are socially situated.

Autonomy has been, and continues to be, a central notion in modern health care ethics. It is understood as the ability to direct one's own life and to make one's own decisions. It is generally seen as having two components: control of one's own actions (that is, the absence of constraint) and the capacity for rational deliberation. The focus of discussions of autonomy within bioethics has typically been patient autonomy. The point generally made here is that competent patients have the right - both ethically and legally - to exercise a significant degree of control over their own health care. The relational perspective on autonomy, as it gains prominence within the health care ethics literature, will have important implications for a wide range of issues, including among others our understandings of informed consent, advocacy and confidentiality. The focus of this article, however, is the implications of the relational perspective for our understanding of the professional autonomy of nurses.

\section{Professional autonomy}

Autonomy is a notion that applies to more than just patients; it also applies to health professionals. Although respect for patient autonomy means that patients should have (other things being equal) as much control as possible over their own care, respect for professional autonomy means allowing professionals to have 
substantial control over professional practice, including significant room for exercise of their judgement.

A 'professional' is (roughly) a member of a self-regulating occupational group granted (usually by legislation) the exclusive right to practice in a particular field. Standard examples of professionals in this sense include physicians, nurses, lawyers and engineers. (Which occupational groups will count as professions, in this model, will vary according to jurisdiction. In some provinces in Canada, for example, social work is a regulated profession, while in others it is not. Although the argument here applies most strongly to the legislated professions, it will apply also, with varying degrees of strength, to other protected and service-orientated occupational groups.)

Nurses have not always been members of a 'profession' in the sense intended here; hence they have not always been accorded professional autonomy. During the American Civil War, for example, the very word 'nurse' could be used to describe a wide range of trained and untrained caregivers. ${ }^{3}$ During the early years of professionalization, nurses were often told to think of the physician-nurse-patient triad as a family, with the physician as the head of the family and the nurse playing a watchful supportive role. ${ }^{4}$ As nursing roles and educational experiences have become standardized, their recognition as a profession has grown. In most modern health care systems, nursing is a licensed, selfregulating profession. Today, nurses have their own professional standards, which imply a right and a wrong way of doing things; no physician order has sufficient moral weight to override those.

The concept of 'professional autonomy' applies to nurses both as a profession and as individuals. As it applies to the profession of nursing, we use the term 'professional autonomy' to indicate the privilege of self-governance. Nurses - like other professionals in such as medicine, law, and engineering - are given the freedom to set, within broad limits, their own standards and to enforce those standards among their members. Today, in modern health care systems, the members of the nursing profession, as a group, are given by society the privilege of setting their own standards of both technical and ethical excellence. Thus, professional bodies typically have the authority to determine educational and licensing standards, to set and enforce standards of technical excellence and ethical propriety, and to grant and revoke licences to practice. This relative freedom that the nursing profession has from outside scrutiny and control constitutes an important kind of autonomy.

As it applies to individual nurses, the notion of professional autonomy has to do with the ability of particular nurses to make at least some decisions that are not subject to authoritative review by those outside of the profession. When we speak of the professional autonomy of an individual nurse, what we are really considering is the right - indeed, the responsibility - of a member of the nursing profession to act according to the shared standards of that profession. Professional autonomy implies the right to exercise professional judgement - in adherence to professional standards - in the face of countervailing pressures from institutional authorities, disagreement with members of other professions, or inappropriate demands on the part of patients or clients or the general public.

For example, professional autonomy provides justification for nurses acting according to their own professional judgement, rather than simply being told by 
physicians what to do. The professional autonomy that nurses so rightly claim means that nursing expertise carries with it its own authority. It means that nursing expertise is independent of, rather than subordinate to, medical expertise. Even when nurses are carrying out physicians' orders, they typically retain a sphere of autonomous judgement regarding how those orders are fulfilled. Nurses receive formal training and gain experience in activities about which physicians typically know less. Nurses may (depending upon specialization) know more, for example, than physicians do about performing phlebotomy or the appropriate procedures for sterile dressings. When a physician's orders conflict with nursing standards or with a nurse's expert judgement, the nurse's professional autonomy implies a right to object.

\section{Sources of autonomy}

What is the source of the professional autonomy claimed by both the profession and the individual nurse? The notion of 'relational' autonomy has recently gained prominence as a reaction against the failings of the more traditional, liberal, understanding of the concept. The liberal understanding of autonomy is accused by critics of assuming an atomistic model of human agency and interaction. Such a model involves a 'false conceptualization of individuals as capable of existing apart from any social relationships, as linked together only by voluntaristic social ties $^{\prime 2} .^{2}$ In this liberal atomistic model, moral agents are seen as limited only by their own values and capacities, and all that other agents need to do by way of respecting their autonomy is to refrain from interfering with the courses of action that agents choose. According to critics of this model, however, human experience - and, in particular, the experience of women - is better characterized as involving networks of relationships and interdependencies, which are, for the most part, neither chosen nor optional. Thus, to focus on autonomy in the individualistic sense is misguided; this criticism seems even more apt within the domain of health care, suffused as it is with relationships of care and dependency.

Yet feminist scholars have been appropriately hesitant to do away with the notion of autonomy altogether. As Donchin notes: 'Appeals to autonomy as a right to make certain personal decisions without interference ... has an emancipatory aim that can be effective in resisting the authority and overvaluation of traditional institutions ...' ${ }^{2}$ Thus, rather than giving up on the notion of autonomy as radically misconceived, a number of feminist scholars have chosen to reconceptualize it, based upon a more accurate understanding of humans as deeply interconnected and interdependent. The revised picture of autonomy that has resulted has come to be known as 'relational autonomy'.

An understanding of relational autonomy, as explicated by Susan Sherwin, requires a focus on the importance of supportive social conditions for fostering autonomous action. ${ }^{1}$ In such a view, individual autonomy is socially constructed; that is, the capacity and opportunity for autonomous action is dependent upon our particular social relationships and the power structures in which we are embedded. Autonomy requires more than mere freedom from interference; it requires that one's relationships with particular individuals and institutions be constituted in such a way as to give one genuine opportunities for choice. 
Autonomy, understood as it traditionally is in terms of negative rights (rights to noninterference) can be a hollow thing when the world around presents vanishingly few real options.

In particular, Sherwin notes that effective autonomy is best achieved when the social conditions that support it are in place. Those social conditions will include not just the material security required in order for the agent to have a range of options, but supportive structures - both personal and political - that give one the confidence to take charge of choices. Although the individualistic understanding of autonomy identifies it with independence, the relational understanding of autonomy sees that persons are never fully independent and seeks instead to find ways to facilitate meaningful self-direction within an overall context of interdependency.

It may be wondered whether there is anything new here. Did anyone ever really suppose that agents could act autonomously independent of their context? Is it not obvious that we all face limits of various kinds? Tom Beauchamp and James Childress (prominent bioethicists, frequently targeted by advocates of relational views of autonomy as promoting an overly individualistic view) themselves admit that autonomy is in part context dependent. They dismiss critics with the brief concession that '[c]ommunal life and human relationships provide the matrix for the development of the self, and no defensible theory of autonomy denies this fact'. ${ }^{5}$ However, as Carolyn Ells points out, this response is unsatisfactory. Although traditional views (such as that of Beauchamp and Childress) may be consistent with attention to the relational aspects of autonomy, the important question is whether traditional views in practice result in sufficient regard for such factors. ${ }^{6}$

\section{Extending the relational view}

It is crucial to see that nothing in Sherwin's or Donchin's work on autonomy implies that autonomy is relational only for individuals qua moral agents. Although the main subjects of their discussions are indeed individual moral agents - more specifically, disempowered moral agents - the arguments advanced by these scholars are intended, I take it, to reveal the nature of autonomy in general. If the relational understanding of autonomy is indeed the appropriate one, then it ought to apply to other sorts of entities that are capable of undertaking autonomous action. I argue that the relational understanding of autonomy can indeed be applied successfully to other sorts of autonomy. In particular, I argue that professional autonomy - the autonomy of both the profession as a collective and individual nurses in their work - is relational in nature. That is, I contend that professional autonomy finds its sources in supportive social relations and is threatened when those relations are either weak or absent.

\section{Autonomy of the profession}

In what sense, then, should professional autonomy be understood as relational, as it applies to the profession of nursing? The most obvious way in which the autonomy of the profession depends on social structures is in the fact that 
nursing, as a self-governing profession, depends on legislation - an external enabling factor - for its very existence. The privilege of self-regulation is granted by society, usually by means of provincial or state legislation. Thus, the profession's ability to grant licences, for example, and to take legal action against those who attempt to practice without a licence, is a direct result of empowering legislation. It is the consent of society - represented by the executive and legislative branches of government - that gives the profession this range of freedom and authority.

Furthermore, the relative autonomy of the profession as a group results, in part, from the reluctance of courts to question the wisdom of standards of proficiency and ethical conduct set by professional bodies. The relative freedom from judicial review enjoyed by most professions finds its source in the common-law understanding that, for the most part, only members of a given profession possess the expertise required to judge the standards set by that profession.7,8 Professions may have either more or less autonomy, depending on the extent to which the courts are willing to defer to the profession on questions such as this. As it happens, most professions enjoy a great deal of autonomy in this regard.

The freedom that the nursing profession has to regulate the activities of its own members is therefore deeply influenced by the profession's relationship with other segments of society, including the executive, legislative and judicial branches of government.

\section{Autonomy of the professional}

Next, in what sense should professional autonomy be understood as relational as it applies to individual nurses? The ability to do the things that nurses do depends crucially on a whole range of social relations and social institutions. Nurses' freedom to care for patients according to their best judgement, for example, is a direct result of their membership of a supporting institution, namely a self-regulating professional body. When they act according to the shared standards of their profession, their colleagues will (normally) lend them their support.

Individual nurses' capacity for autonomous action depends on a number of features of the health care institution within which they practice. In an article on accepting and refusing assignments, Judith Powers notes the importance of an 'enabling practice environment', which 'supports autonomous nursing giving nurses the opportunity, the authority, and the accountability to identify and solve practice related problems'. ${ }^{9}$ Among the factors Powers points to as enabling autonomous nursing is adequate staffing. Without this nurses may find their ability - their freedom - to meet the demands of professional standards jeopardized. Other examples of ways in which health institutions can support autonomous nursing include providing ancillary personnel to assist nurses with such non-nursing tasks as laundry and food tray pick-up, and supporting 'collaborative practice through monthly meetings between unit nurses and the physicians who work on those units'.10

Regulations also play an important role in facilitating - and limiting - individual nurses' autonomy. They do not generally have the autonomy, for example, to engage in the range of practices granted by legislation to physicians. As a 
particular example, Cullen notes that nurses' '[d]ecision-making autonomy is inhibited in the UK by the restrictions on nurse prescribing' ${ }^{11}$

Some nursing roles provide for a greater degree of autonomy, by design. Nurse practitioners, for example, are granted autonomy within a broader range of practices than are registered nurses. Even when legislation permits autonomous practice (e.g. for nurse practitioners), the ability actually to practice autonomously depends upon a range of factors, including public perceptions, institutional arrangements and the support and respect of other health professions. Cullen notes that 'the development of clearly defined, accessible, cost effective nursing care will open up further opportunities' for nurse practitioners to practice autonomously. ${ }^{11}$ The greater ability of nurse practitioners to practice autonomously springs from a combination of additional education and enabling legislation, both of which find their source in social relations of the sort that make this additional autonomy count as relational.

If we are to see clearly the distinction between personal and professional autonomy, it may help to look at an example of (relational) personal autonomy as it applies to nurses' work within a professional context. An example of the degree to which nurses' personal autonomy, within their work environment, is relational can be seen in cases of conscientious objection. To the extent to which nurses have the freedom to decline assignments that they oppose ethically, they have this freedom because their rights of conscience are supported by their professional code of conduct, by institutional policies, and by the courts. ${ }^{12}$ It is important to see, however, that this is an instance of personal, not professional autonomy. The right not to participate in activities that one finds objectionable springs not from one's membership of a profession, but from one's dignity as a human being. Indeed, membership of the nursing profession puts distinct limits on one's personal autonomy. ${ }^{13}$ For example, as Davino notes, 'once you begin treating a patient, you're legally responsible for him until he has been placed in the care of someone else' ${ }^{12}$ This requirement applies regardless of whether one has reason to object, for personal reasons, to the assignment.

\section{Implications of a relational model}

What implications spring from understanding nurses' professional autonomy as relational? Two spring readily to mind.

First, understanding autonomy as relational may help nurses (or nursing students) to understand better the differences between their own capacities for autonomous action and the capacities of the patients for whom they care. As Michael Yeo notes: 'Power, knowledge, and vulnerability are not evenly balanced in the client-professional relationship' ${ }^{14}$ It is all too easy for people in positions of relative power to underestimate their own advantages. A focus on the relational nature of autonomy reminds professionals that their own capacities for autonomous action - including their skills, their education, their self-confidence - have their source in certain enabling experiences and relationships that may not be similarly available to particular patients. As Donchin points out, 'Some women are inevitably better prepared to be assertive than others because social, educational, and economic class obviously influence one's self-assurance in the face of 
authority' $^{2}$ This realization may facilitate appropriate empathy, on the part of nurses, for disempowered patients.

Secondly, a relational understanding of nurse autonomy may help us to understand better those situations in which nurses themselves are seen as having inadequate autonomy. The study of the relational nature of autonomy, as exemplified by Sherwin and Donchin, is rooted in a desire to understand better the relative lack of autonomy of oppressed groups. Applying the lens of relationality to professional autonomy may seem odd to some because professionals have traditionally been understood as enjoying a relative abundance of autonomy. Indeed, the scope of autonomous judgement is one of the identifying marks of a professional, but it is clear that not all professions enjoy an equal scope of autonomous action. Health care, in particular, is notoriously hierarchical in this regard. Physicians have traditionally had the lion's share of authority, with nursing and pharmacy, for example, only more recently asserting themselves as autonomous professions with their own bodies of knowledge and their own responsibilities to patients. As nurses and other health care professionals move towards greater autonomy, and also towards collaboration with (rather than subordination to) physicians, it will be crucial to understand the social and institutional factors that enable autonomous action. Clearly, a relational understanding of autonomy is essential here. Autonomy does not and cannot mean independence. For nurses, increasing professional autonomy must mean finding ways to facilitate meaningful selfdirection within the context of an interdependent health care team.

\section{References}

1 Sherwin S. A relational approach to autonomy in health care. In: Sherwin S ed. The politics of women's health: exploring agency and autonomy. Philadelphia, PA: Temple University Press, 1998: 19-47.

2 Donchin A. Reworking autonomy: toward a feminist perspective. Camb Q Healthc Ethics 1995; 4: 44-55.

3 Culpepper MM, Adams PG. Nursing in the Civil War. Am J Nurs 1988; 88: 981-84.

4 Davies C, Savage J, Smith R. Doctors and nurses: changing family values? BMJ 1999; 319: 463-64.

5 Beauchamp TL, Childress JF. Principles of biomedical ethics, fourth edition. New York: Oxford University Press, 1994.

6 Ells C. Shifting the autonomy debate to theory as ideology. J Med Philos 2001; 26: 417-30.

7 Prosterman P. Who sets the standard? What happens when a court decides to put an entire profession on trial? CA Magazine 1992; 125(4): 46-50.

8 Creighton H. The nurse as expert witness. Nurs Manage 1988; 19(8): 22-23.

9 Powers JL. Accepting and refusing assignments. Nurs Manage 1993; 24(9): 64-67.

10 Eubanks P. Nursing restructuring renews focus on patient-centered care. Hospitals 1990; 64(8): 60-62.

11 Cullen C. Autonomy and the nurse practitioner. Nurs Stand 2000; 14(21): 53-56.

12 Davino M. You don't have to care for every patient. RN 1996; 59(9): 63-67.

13 MacDonald C. Clinical standards and the structure of professional obligation. Prof Ethics 2000; 8: 7-17.

14 Yeo M. A primer in ethical theory. In: Yeo M, Moorhouse A eds. Concepts and cases in nursing ethics, second edition. Peterborough, ON: Broadview, 1996: 27-55. 